\title{
Thoracoscopic Repair of Oesophageal Atresia: Results of a Selective Approach
}

\author{
Carmen Dingemann ${ }^{1}$ Christoph Zoeller ${ }^{1}$ Benno Ure ${ }^{1}$ \\ ${ }^{1}$ Department of Pediatric Surgery, Hannover Medical School, \\ Hannover, Germany \\ Eur J Pediatr Surg 2013;23:14-18. \\ Address for correspondence and reprint requests Carmen \\ Dingemann, MD, Department of Pediatric Surgery, Hannover Medical \\ School, Carl-Neuberg-Strasse 1, Hannover 30625, Germany \\ (e-mail: dingemann.carmen@mh-hannover.de).
}

\begin{abstract}
Keywords

- oesophageal atresia

- tracheoesophageal fistula

- thoracoscopy

- neonate

- outcome

Introduction The repair of oesophageal atresia (OA) and tracheoesophageal fistula (TOF) may be routinely performed via thoracoscopy. However, data on the feasibility and efficacy of thoracoscopic OA/TOF repair are scarce and some authors reported a high rate of anastomotic leak. The aim of this study was to evaluate our concept of OA/ TOF repair which includes specific selection of patients and a selective surgical approach.

Patients and Methods The study was approved by the Institutional Review Board and written informed consent was obtained from all guardians for anonymized data analysis. All patients undergoing OA/TOF repair from June 2001 to December 2011 were included in this analysis. Thoracoscopy was used in cardiorespiratory stable newborns with OA/TOF and a birthweight of $\geq 2000 \mathrm{~g}$. In case of any intraoperative adverse events, lack of progress for $\sim 15$ minutes, or anastomosis under tension, the procedure was converted to open thoracotomy. Study endpoints were conversion rate and postoperative complications.

Results A total of 44 newborns with OA/TOF were operated, of whom 22 (6 females, 16 males) met our criteria for a thoracoscopic approach. The mean birthweight of thoracoscopically operated patients was 2760 (2020 to 3960) g, 7 were $<36$ weeks of gestation. The mean operative time was 142 (75 to 220) minutes. Thoracoscopy was converted to thoracotomy in eight patients due to problems with exposition $(n=2)$, ventilation ( $n=3)$, anastomosis under tension $(n=2)$, or bleeding ( $n=1$, no transfusion). There was no anastomotic leak in the group of patients who underwent successful thoracoscopic repair, but one recurrence of TOF. Two anastomotic leaks emerged in patients in whom the operation was converted. A total of 7 out of the 22 children required endoscopic dilatation. There was no mortality during a mean follow-up of 5.5 years (43 days to 10.6 years).

Conclusion Our approach included meticulous patient selection and prompt conversion in case of any adverse events. With this approach, thoracoscopic repair of OA/TOF can be safely performed achieving excellent results and a low rate of complications.
\end{abstract}

\section{Introduction}

Oesophageal atresia (OA) with/without tracheoesophageal fistula (TOF) is a rare congenital malformation occurring in

received

May 15, 2012

accepted after revision

July 18,2012

published online

October 23, 2012

1 of 5000 newborns. ${ }^{1}$ The survival rate of patients with OA has increased significantly during the last decades, ${ }^{2,3}$ and today exceeds $90 \%{ }^{2}$ Most patients survive without associated severe malformations. The high mortality of very low

(c) 2013 Georg Thieme Verlag KG Stuttgart · New York
DOI http://dx.doi.org/ 10.1055/s-0032-1326953. ISSN 0939-7248. 
birthweight patients with TOF and patients with severe cardiac malformations has also decreased significantly. ${ }^{4}$

In many surgical centers, open, right-sided muscle-sparing thoracotomy is the standard approach for repair of $\mathrm{OA} /$ TOF. $^{3,5,6}$ The learning curve of the open approach is well known and the postoperative results are predictable., ${ }^{4,5}$

Today, advances in pediatric thoracoscopy allow sophisticated procedures, even in the confined anatomic spaces of neonates, ${ }^{3}$ and thoracoscopic repair of OA/TOF has gained increasing acceptance. In 1999, the first thoracoscopic repair of isolated $\mathrm{OA}$ was performed in a 2-month-old infant. ${ }^{7}$ After 1 year, the first totally thoracoscopic repair of an atresia with distal fistula was realized in a newborn. ${ }^{8}$ These milestones allowed for a more widespread adoption of this technique and an increasing number of pediatric surgical units are now performing minimally invasive $\mathrm{OA} /$ TOF repair. ${ }^{1,9}$

Numerous authors reported on excellent feasibility of thoracoscopic OA/TOF repair. ${ }^{1,3,6,9-14}$ However, the rate of postoperative anastomotic leak seems to be higher compared with the open approach. $6,9,11$

In our center, thoracoscopic repair of uncomplicated $\mathrm{OA} /$ TOF is routinely performed in carefully selected patients. The decision for thoracoscopy is based on precise selection criteria. In case of any adverse events, the decision for a conversion is made in close cooperation with the anesthetic team.

Aim of this study was to evaluate safety and efficacy of thoracoscopic repair of OA/TOF using our selective approach. Endpoints were conversion rate and perioperative complications.

\section{Patients and Methods}

The study was approved by the Institutional Ethics Committee (approval number: 1306-2012), and written informed consent was obtained from all guardians for anonymized data analysis and publication. A retrospective chart review of all consecutive patients undergoing OA/TOF repair between June 2001 and December 2011 was performed.

Table 1 Reason for conversion from thoracoscopic approach for OA/TOF repair to open thoracotomy

\begin{tabular}{|l|l|l|}
\hline Reason for conversion & $\begin{array}{l}\text { No. of } \\
\text { patients }\end{array}$ & $\%$ \\
\hline Insufficient surgical exposition & 2 & 9 \\
\hline Ventilation problems & 3 & 14 \\
\hline Anastomosis under tension & 2 & 9 \\
\hline Bleeding & $1^{\text {a }}$ & 5 \\
\hline Total & 8 & 36 \\
\hline
\end{tabular}

Abbreviations: OA, oesophageal atresia; TOF, tracheoesophageal fistula. ${ }^{a}$ No need for blood transfusion.
Data collected included birthweight, associated malformations, age at surgery, operative time, conversion rate, and intra- and postoperative complications.

All patients underwent standardized preoperative assessment including full physical examination, chest radiograph, echocardiogram, and renal ultrasound.

Criteria for the thoracoscopic approach were suspected short-gap OA/TOF, birthweight $\geq 2000$ g, $\leq$ one major associated malformation, and cardiorespiratory stability (no medical cardiac support and no mechanical ventilation).

\section{Operative Technique}

Newborns were positioned semiprone with the right side slightly elevated and prepared for open thoracotomy should this have proved necessary. Initially, a $5 \mathrm{~mm}$ port for the videoscope was placed one intercostal space below the tip of the scapula, followed by two $3.5 \mathrm{~mm}$ working ports placed under direct vision in the 7th to 8th intercostal space paravertebrally in the anterior axillary line. Creating an intrathoracic pressure of 3 to $5 \mathrm{~mm} \mathrm{Hg}, \mathrm{CO}_{2}$ insufflation was initiated with 1 to $2 \mathrm{~L} / \mathrm{min}$.

The azygos vein was not routinely dissected. Identification of the distal fistula and suture ligation with 4/0 Vicryl was performed to facilitate ventilation. The upper pouch was identified placing downward pressure on the nasogastric tube. Following transection of the distal fistula, the first suture for the anastomosis was placed and the knot tied to avoid tension. Hereafter, the proximal oesophagus was opened, and a 6- to 8-Ch nasogastric tube was advanced through the distal oesophagus into the stomach under direct vision. The anastomosis was performed circumferentially using 5/0 Vicryl interrupted sutures. A chest tube was not routinely inserted.

Standard perioperative monitoring included the following: pulse oximetry, electrocardiogram, end tidal $\mathrm{CO}_{2}$ measurement, inhaled volatile agent concentration, invasive blood pressure measurement, arterial blood gas measurement, and temperature.

In case of any intraoperative adverse events ( - Table 1 ) or lack of progress for $\sim 15$ minutes, the procedure was converted to open muscle-sparing thoracotomy.

Postoperative monitoring was performed in a pediatric intensive care unit. Weaning and extubation was aimed at the earliest possible time point. Enteral feeding was initiated on the first postoperative day. The nasogastric tube remained in situ until day 10 post surgery. A contrast study was not routinely performed before initiating oral feeds.

Data are quoted as median and interquartile ranges.

\section{Results}

A total of 44 consecutive patients with OA/TOF were treated in our center during the study period. Total 22 patients ( 6 female, 16 male) met our criteria for thoracoscopic repair of OA/TOF and underwent primary thoracoscopic approach.

A total of 22 infants (95\%) had OA with TOF ( $n=19$ distal TOF, $n=1$ proximal TOF, $n=1$ both proximal and distal TOF) and one (5\%) had isolated OA. 
Table 2 Associated anomalies in the group of 22 patients undergoing thoracoscopic repair of OA/TOF (anomalies were present in 9/22 patients)

\begin{tabular}{|l|l|}
\hline Associated anomaly & No. of patients \\
\hline Gastrointestinal malformations & 3 \\
Jejunal atresia & 1 \\
Imperforate anus & 2 \\
\hline Cardiovascular malformations & 7 \\
ASD & 4 \\
VSD & 3 \\
\hline Other & 5 \\
Trisomy 21 & 1 \\
Tethered cord & 1 \\
Hydrocephalus internus & 1 \\
Vertebral anomalies & 1 \\
VUR $>$ Grade 3 & 1 \\
\hline
\end{tabular}

Abbreviations: ASD, atrial septal defect; VSD, ventricular septal defect; VUR, vesicoureteral reflux.

The mean birthweight was $2760 \mathrm{~g}$ (2020 to 3960). Seven of the patients (32\%) were born prematurely ( $\leq 36$ weeks of gestation).

Concomitant anomalies were encountered in nine patients (41\%) (-Table 2). Age at surgery was $\leq 1$ day $(n=2), \leq 2$ days $(n=6), \leq 3$ days $(n=11), \leq 4$ days $(n=2)$, and $\leq 5$ days $(n=1)$. Mean operative time was 142 (75 to 220 ) minutes.

Eight patients (36\%) underwent conversion from a thoracoscopic procedure to an open thoracotomy for various reasons (-Table 1 ).

There was no anastomotic leak in the group of patients who underwent successful thoracoscopic repair, but one recurrence of TOF ( - Table 3 ). This was the first patient of our series who underwent open revision and a successful repair.

Anastomotic leak emerged in two patients $(9 \%)$ in whom thoracoscopy had to be converted. One leak could be managed conservatively and spontaneously resolved, the second patient with a leak underwent thoracotomy and insertion of chest drain for pleural effusion. An oesophageal stricture requiring at least one endoscopic dilatation emerged in 7 of the 22 patients ( - Table 3 ).

There was no mortality during a mean follow-up of 5.5 years (43 days to 10.6 years).

\section{Discussion}

Recent advances in minimally invasive surgery in infants and children have allowed for a wide expansion of applications over the last decade, ${ }^{1}$ hence thoracoscopic repair of OA /TOF has gained increasing acceptance. ${ }^{6,10,15}$ The greatest advantage of a thoracoscopic approach is avoiding a posterolateral thoracotomy in a neonate. ${ }^{1}$ Our group and other authors have recently demonstrated that thoracoscopy in children is associated with significantly less mid-term musculoskeletal sequelae additional to a better cosmetic outcome compared with thoracotomy. ${ }^{1,6,12,16}$ Furthermore, thoracoscopy provides an excellent visualization of the anatomy within the confined spaces of the neonate because of its magnification which facilitates the identification of the fistula. ${ }^{1,6,12,13}$

Despite all advantages, minimally invasive repair of $\mathrm{OA} /$ TOF remains a technically challenging operation ${ }^{6}$ with the suturing of the anastomosis being the major hurdle. ${ }^{1,11}$

It is a common consensus that surgical expertise and advanced thoracoscopic skills are required to complete this operation successfully. $^{10-12}$

Besides surgeon's expertise, we strongly believe that meticulous selection of patients contributes to the success of this minimally invasive procedure. In the literature available, no specific selection criteria have been established for the thoracoscopic approach. We suggest the use of the aforementioned criteria to provide best possible treatment of OA/TOF patients and to ensure a postoperative outcome at least similar to the open operation.

It is well known that length of the oesophageal gap and associated major malformations are important contributors to significant complications in $\mathrm{OA} / \mathrm{TOF}^{5}$ A cornerstone of patient selection is a careful preoperative work-up. In our series, the majority of the children (77\%) were operated on day 2 or 3 of life after completion of comprehensive diagnostic assessment.

It has been postulated that OA/TOF repair can be difficult in newborns $\leq 2000 \mathrm{~g}$ and also in neonates with significant lung disease. ${ }^{12}$ This is a part of the rationale of our concept using meticulous selection criteria. The thoracoscopic approach was only performed in cardiorespiratory stable patients with uncomplicated OA/TOF and a birthweight of $\geq 2000$ g.

Comparable studies about thoracoscopic OA/TOF repair included patients with birthweights $\leq 2000 \mathrm{~g}$ starting from

Table 3 Postoperative complications (thoracoscopic repair of OA/TOF versus converted operations) in a group of 22 patients

\begin{tabular}{|l|l|l|}
\hline Postoperative complications & Thoracoscopy & Conversion \\
\hline Anastomotic leak & 0 & $2(9 \%)$ \\
\hline Recurrent fistula & $1(5 \%)^{\mathrm{b}}$ & 0 \\
\hline Anastomotic stricture $^{\mathrm{a}}$ & $4(18 \%)$ & $3(14 \%)$ \\
\hline Mortality & 0 & 0 \\
\hline Total & $5(23 \%)$ & $5(23 \%)$ \\
\hline
\end{tabular}

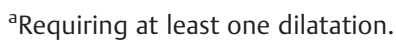

${ }^{\mathrm{b}}$ First patient of our series. 
Table 4 Comparison of our series with previous reports using thoracoscopy for repair of OA/TOF

\begin{tabular}{|l|l|l|l|l|l|l|}
\hline Author & No. of patients & $\begin{array}{l}\text { Conversion } \\
(\%)\end{array}$ & $\begin{array}{l}\text { Anastomotic } \\
\text { leak }\end{array}$ & Recurrent fistula & $\begin{array}{l}\text { Anastomotic } \\
\text { stricture }^{\text {a }}\end{array}$ & \begin{tabular}{l} 
Mortality (\%) \\
\hline van der Zee and Bax
\end{tabular} \\
\hline MacKinlay & 51 & 4 & $18 \%$ & $4 \%$ & $45 \%$ & 2 \\
\hline Patkowsk et al $^{11}$ & 26 & 4 & $27 \%$ & $4 \%$ & $35 \%$ & 12 \\
\hline Holcomb et al $^{12}$ & 104 & 0 & $13 \%$ & $0 \%$ & $17 \%$ & 13 \\
\hline Szavay et al & 23 & 5 & $8 \%$ & $2 \%$ & $32 \%$ & 3 \\
\hline Current study & 25 & 32 & $4 \%$ & $4 \%$ & n.a. & n.a. \\
\hline
\end{tabular}

Abbreviation: na, not available.

${ }^{\text {a }}$ Requiring at least one oesophageal dilatation.

b In cases where thoracoscopy had to be converted to open thoracotomy.

'First patient of our series.

$1000 \mathrm{~g}$ and severe congenital heart disease, such as double outlet right ventricle and hypoplastic right heart. 6,9,11,12 Two newborns died after thoracoscopic repair of OA/TOF from severe congenital heart disease, of whom one baby required an emergency intubation related to congenital heart disease in which the endotracheal tube was thrust through the fistula closure on the trachea after thoracoscopic repair. ${ }^{12}$ Other authors reported on a $1.4 \mathrm{~kg}$ child that died postoperatively from further undiagnosed anomalies. ${ }^{9}$ In all cited studies, mortality is a relevant issue (-Table 4). In our series, no deaths after thoracoscopic OA/TOF repair were observed, and we believe that our concept of carefully selected patients contributes to this favorable outcome.

Furthermore, we believe that our concept of early conversion to thoracotomy in case of any adverse events contributes to a low rate of complications. Compared with other studies (-Table 4), conversion rate in our series was high. ${ }^{6,9,11,12}$ Only one other study by Szavay et $\mathrm{ll}^{14}$ reports a similarly high conversion rate. The main reason for conversion mentioned by the authors was increasing intraoperative hypoxemia, following the concept of a selective approach and consideration of other than surgical aspects.

Anastomotic leak can be devastating and may result in mortality as a result of mediastinitis and irreversible sepsis. ${ }^{5}$ Tension on the suture line is obviously a contributing factor to the possibility of a leak. ${ }^{5}$ In our study, an anastomosis under tension was one of the reasons for conversion. The incidence of anastomotic leak in our series was low and compares favorably with other reports in literature on conventional operation, 6,9,11 (-Table 4). The two observed leaks only occurred after conversion reflecting difficult intraoperative circumstances.

Anastomotic stricture represents the most common cause of revisional surgery in children with $\mathrm{OA} / \mathrm{TOF}^{5}$ The majority of the studies report a stricture rate between 17 and $45 \%$, 6,11 (-Table 4). In our series, the rate of an anastomotic stricture requiring at least one dilatation is comparable to the reported numbers. However, all strictures responded well to endoscopic dilatation and none of the patients needed operative revision.

\section{Conclusion}

Thoracoscopic repair of OA/TOF remains a technically challenging operation. However, using standardized meticulous patient selection and prompt conversion in case of any adverse events, thoracoscopic repair of OA/TOF can be safely performed achieving excellent results and a low rate of complications.

\section{Conflict of Interest}

None

\section{References}

1 Rothenberg SS. Thoracoscopic repair of esophageal atresia and tracheo-esophageal fistula in neonates: evolution of a technique. J Laparoendosc Adv Surg Tech A 2012;22(2):195-199

2 Goyal A, Jones MO, Couriel JM, Losty PD. Oesophageal atresia and tracheo-oesophageal fistula. Arch Dis Child Fetal Neonatal Ed 2006;91(5):F381-F384

3 Rothenberg SS. Thoracoscopic repair of tracheoesophageal fistula in newborns. J Pediatr Surg 2002;37(6):869-872

4 Rintala RJ, Sistonen S, Pakarinen MP. Outcome of esophageal atresia beyond childhood. Semin Pediatr Surg 2009;18(1):50-56

5 Mortell AE, Azizkhan RG. Esophageal atresia repair with thoracotomy: the Cincinnati contemporary experience. Semin Pediatr Surg 2009;18(1):12-19

6 van der Zee DC, Bax KN. Thoracoscopic treatment of esophageal atresia with distal fistula and of tracheomalacia. Semin Pediatr Surg 2007;16(4):224-230

7 Lobe TE, Rothenberg S, Waldschmidt J, et al. Thoracoscopic repair of esophageal atresia in an infant: a surgical first. Pediatr Endosurg Innov Tech 1999;3(3):141-148

8 Rothenberg SS. Thoracoscopic repair of a tracheoesophageal fistula in a newborn infant. Pediatr Endosurg Innov Tech 2000;4(4): 289-294

9 MacKinlay GA. Esophageal atresia surgery in the 21st century. Semin Pediatr Surg 2009;18(1):20-22

10 Allal H, Kalfa N, Lopez M, et al. Benefits of the thoracoscopic approach for short- or long-gap esophageal atresia.J Laparoendosc Adv Surg Tech A 2005;15(6):673-677

11 Patkowsk D, Rysiakiewicz K, Jaworski W, et al. Thoracoscopic repair of tracheoesophageal fistula and esophageal atresia. J Laparoendosc Adv Surg Tech A 2009;19(Suppl 1):S19-S22 
18 Thoracoscopic Repair of Oesophageal Atresia Dingemann et al.

12 Holcomb GW III, Rothenberg SS, Bax KM, et al. Thoracoscopic repair of esophageal atresia and tracheoesophageal fistula: a multi-institutional analysis. Ann Surg 2005;242(3):422-428, discussion 428-430

13 Wong KK, Tam PK. Thoracoscopic repair of esophageal atresia through the right chest in neonates with right-sided aortic arch.J Laparoendosc Adv Surg Tech A 2010;20(4):403-404

14 Szavay PO, Zundel S, Blumenstock G, et al. Perioperative outcome of patients with esophageal atresia and tracheo-esophageal fistula undergoing open versus thoracoscopic surgery. J Laparoendosc Adv Surg Tech A 2011;21(5):439-443
15 Nguyen T, Zainabadi K, Bui T, Emil S, Gelfand D, Nguyen N. Thoracoscopic repair of esophageal atresia and tracheoesophageal fistula: lessons learned. J Laparoendosc Adv Surg Tech A 2006;16 (2):174-178

16 Lawal TA, Gosemann JH, Kuebler JF, Glüer S, Ure BM. Thoracoscopy versus thoracotomy improves midterm musculoskeletal status and cosmesis in infants and children. Ann Thorac Surg 2009; $87(1): 224-228$ 